Article

\title{
Experimental Investigation of Copper Mesh Substrate with Selective Wettability to Separate Oil/Water Mixture
}

\author{
Jia Yuan ${ }^{1,2}$, Chenyi Cui ${ }^{1}$, Baojin Qi ${ }^{1,2, *}$, Jinjia Wei ${ }^{1,3}$ and Mumtaz A. Qaisrani ${ }^{3}$ \\ 1 School of Chemical Engineering and Technology, Xi'an Jiaotong University, Xi'an 710049, China; \\ yj2551241405@stu.xjtu.edu.cn (J.Y.); ccy8600@stu.xjtu.edu.cn (C.C.); jjwei@xjtu.edu.cn (J.W.) \\ 2 Xi'an Jiaotong University Suzhou Academy, Suzhou 215123, China \\ 3 State Key Laboratory of Multiphase Flow in Power Engineering, Xi'an Jiaotong University, Xi'an 710049, \\ China; mumtazqaisrani@yahoo.com \\ * Correspondence: bjqi@mail.xjtu.edu.cn
}

Received: 20 October 2019; Accepted: 21 November 2019; Published: 29 November 2019

\begin{abstract}
To solve the problem of low efficiency and poor adaptability during complex oil/water mixtures separation, two types of membranes with superhydrophilicity/underwatersuperoleophobicity were successfully fabricated by oxidative reaction and in situ displacement reaction methods. A nanoneedle $\mathrm{Cu}(\mathrm{OH})_{2}$ structure was generated on the copper mesh substrate by oxidative reaction and feathery micro/nanoscale composite, while $\mathrm{Ag}$ structure was constructed at the surface of copper mesh substrate through in-situ replacement, then, membranes with superhydrophilic/ underwater-superoleophobic properties were separated. The influence of microstructure, wettability of the surface of prepared membranes and the liquid constituents in the separation experiment were studied and the liquid flux and permeation pressure at the membrane were later experimentally investigated. The experimental results show that separation efficiency of both membranes for separating different oil/water mixtures was above $99.8 \%$. However, the separation efficiency of the Ag-CS (Ag on the copper substrate) membrane was obviously higher than that of the $\mathrm{Cu}(\mathrm{OH})_{2}-\mathrm{CS}\left(\mathrm{Cu}(\mathrm{OH})_{2}\right.$ on the copper substrate) membrane after 10 instances of separation because of the micro/nanocomposite structures. By comparison, it was found that the Ag-CS membrane showed a relatively higher permeation pressure but lower liquid flux as compared to $\mathrm{Cu}(\mathrm{OH})_{2}-\mathrm{CS}$ membrane, due to the influence of microscale structure and the wettability of the surface combined. In addition, the outcome for separating the multicomponent oil/water mixture illustrate that the result of TOC (the Total Organic Carbon) test for the $\mathrm{Cu}(\mathrm{OH})_{2}-\mathrm{CS}$ membrane and $\mathrm{Ag}-\mathrm{CS}$ membrane were $31.2 \%$ and $17.7 \%$, respectively, higher than the average of the two oils probably because some oil droplets created due to mutual dissolution passed through the membranes. However, these two fabricated membranes still retained higher separation efficiencies and good adaptability after 10 instances of separation. It was concluded that based on the good performances of the prepared membranes, especially the modified membrane, they have a vast application prospect and can be widely used.
\end{abstract}

Keywords: oil/water separation; superhydrophilic/underwater-superoleophobic membranes; opposite properties; superhydrophobicity/superoleophilicity; selective wettability; micro/nanoscale composite structure

\section{Introduction}

During recent years, large discharge quantities of oily wastewater has attracted the attention of the public, and it also has drawn researchers' interests in the field of fabricating novel materials having higher oil/water separation efficiency. There are two primary ways to generate oily wastewater: the 
first is by releasing the oil-contaminated industrial wastewater; these industries often constitute of petrochemical industries, printing industries, metallurgical-production industries, food-processing industries, and so on [1-6]. Such wastewater has become the most common contaminant all over the world and it has seriously threatened our habitat. The other reason for oily wastewater generation is the large numbers of oil spill incidents and the recent estimates show that nearly two million tons of oil spills into the ocean annually [5-7]. So, a significant quantity of waste oil being disposed into the oceans has not only caused substantial energy loss, but also seriously threatened aquatic life because the spilled oil decreases the oxygen present in the water [8-13]. In addition, the fouling of surfaces is a significant problem that affects not only people' daily lives, but also does harm to industrial production systems, and it could be mitigated via a method by combining particular designed interfaces and further chemical treatments. This is a good technique with broad application prospects.

If the membranes with low surface adhesion to contaminants on the surface could be prepared, it will greatly benefit the lifetime and separation efficiency of the membranes in practical applications [14]. At present, several traditional methods including ultrasonic separation, skimming, centrifugation, combustion, etc., are being widely applied for the oily wastewater separation $[9,15-18]$. Nevertheless, the application range of these techniques is often hampered by some limitations such as the production of secondary pollutants, low efficiency, and the complex operation [3,15,19-21]. Considering the issues above, there's an urgent requirement for novel technologies having characteristics, higher separation efficiency, low operational cost and simple operation for separation of oil/water mixture.

Inspired by the naturally occurring phenomenon of superhydrophobicity at the surface of lotus leaf and goose feathers, scholars have researched and fabricated new membrane-based materials with high separation efficiency of oil/water mixtures. These membrane materials with unique wetting properties have gradually become a hot research topic in the past decade [6,22-24]. Wettability exists as an inherited characteristic of solid surfaces, and it affects the wetting phenomenon as the droplets touch the surface of the solid [25-28]. According to the different wetting phenomena when oil droplets and water droplets touch the solid surface, it can be summarized into four wetting properties, namely: oleophilicity, oleohobicity, hydrophilicity and hydrophobicity. Researchers found that the hierarchical micro/nanostructures could increase the roughness of the solid surface and then enhanced the four-fundamental wetting properties into superoleophilicity, superoleohobicity, superhydrophilicity and superhydrophobicity [29-34] and some organics with lower surface energy could decrease the wettability of liquid and solid surfaces. By employing physical refining as well as chemical treatment approaches such as corrosion, alteration of some substances with lower energy, electric deposition etc., to formulate the micro and nanocomposite structure membrane with relatively lower energy surfaces [20,35]. On the basis of above analyses the membrane-based separation material driven solely by gravity can be divided into two categories: "water-removing" and "oil-removing". The first type material called "water-removing" membrane means the membrane shows "water-loving" and "oil-hating" characteristics, and water easily passes across the membrane; however, oil is blocked over the membrane simultaneously. On the contrary, the membrane of the "oil-removing" material shows "oil-loving" and simultaneously "water-hating" characteristics, and water stops above the membrane while oil can permeate the membrane smoothly [36-39].

Researchers first prepared the superhydrophobic/superoleophilic surface, which could selectively let the oil pass through but stopped the water and the material successfully separated the heavier oil/water mixture $[9,24]$. However, there are two main problems associated with the practical application of the superhydrophobic/superoleophilic membranes: on the one hand, this material is suitable to separate the heavier oils/water, like 1,2-dichloroethane, whose density is heavier than the density of water, but oils having a density lower than water; it becomes complex to practically separate the mixture because the oil cannot touch the membrane even though it could easily pass across the membrane, and is occluded by the lower water layer. In such a situation, placing the separation device obliquely is necessary to separate the mixture smoothly [38-40]. While, on the other hand, as a result of higher viscosity, the oil phase quickly chokes the membrane 
during the separation. Thus, the separation rate can be much lower, and that limits the practical application in the field of oil/water separation [41-43]. Considering the problems above, scholars have investigated the superhydrophilicity/superoleophobicity phenomenon compared with the superhydrophobicity/superoleophilicity of the oil-removing-type material.

After continuous exploration and attempts by many scholars, this material was successfully fabricated [44]. The "water-removing" membrane could ideally avoid the two problems mentioned above to separate oil with a lower density than the water, as water smoothly flows across the superhydrophilic membrane and oil stays above the superoleophobic membrane. Even if it perfectly avoids these two problems, there still remain a few disadvantages of the superhydrophilic/superoleohobic materials. Many "water-removing" materials need to have characteristics with lower surface energy to further modify its solid surface, but actually those materials with lower surface energy are usually fluorine-containing organic matter $[23,31,45,46]$. In that case, the formation process is usually complex and costly, but also the chemical stability of the adapted surface coating is not very effective. Furthermore, the literature shows that the current research hitherto primarily focused on separating the single oil and water mixture. However, it should be noted that the composition of wastewater containing oil varies and was often complex due to presence of different oil components; this certainly yields a high demand for membrane adaptability to the practical applications of oil/water separation $[8,15,36]$.

The current study reports two facile and one-step chemical reaction methods on the copper mesh to fabricate the "water-removing" membrane with superhydrophilicity and underwater-superoleophobicity. The prepared membranes possess a nanoneedle $\mathrm{Cu}(\mathrm{OH})_{2}$ structure and a micro/nanocomposite $\mathrm{Ag}$ structure. With these two easily operable methods, we successfully fabricated the water-removing membranes and experimentally studied the separation efficiency, permeation pressure and fluid flux. In addition, to authenticate the more widespread adaptability of the membranes, the mixture with a single component of oil and water were successfully separated, and the multi-constituents of the $\mathrm{oil} /$ water mixture were experimentally investigated.

\section{Experimental Platform}

\subsection{Materials}

Four-hundred copper mesh substrates were used as obtained. Deionized water was self-prepared. Other reagents including $\mathrm{AgNO}_{3}, \mathrm{HCl}$, Oil Red O (Sudan) etc. from Sinopharm Chemical Reagents Group were of analytical grade and were used without any further purification. Diesel and gasoline were purchased from Sinopec, and sunflower oil was purchased from the supermarket.

\subsection{Sample Preparation}

The copper meshes were sized into $6 \times 6 \mathrm{~cm}^{2}$ fragments for the following use. To make clean membranes, acetone along with ethanol and deionized water in beakers was used to serially soak all the meshes. Beakers were then left in an ultrasonic cleaner for nearly $10 \mathrm{~min}$. In the end, the meshes were dried to remove any remaining contaminants at the surface of the substrate. To eliminate contaminants at the surface of the substrate, the meshes were later dried.

To prepare the $\mathrm{Cu}(\mathrm{OH})_{2}-\mathrm{CS}$ membrane, firstly placing a cleaned copper mesh prepared as above into the $1 \mathrm{M} \mathrm{NaOH}$ and $1 \mathrm{M} \mathrm{K}_{2} \mathrm{~S}_{2} \mathrm{O}_{8}$ mixed solution horizontally for almost an hour, the prepared membrane was then rinsed with deionized water and dried at room temperature. Then, the $\mathrm{Cu}(\mathrm{OH})_{2}-\mathrm{CS}$ membrane was obtained. To fabricate the Ag on the copper substrate (Ag-CS) membrane, $100 \mathrm{~mL}$ $0.1 \mathrm{M} \mathrm{AgNO}_{3}$ solution was first prepared, and a piece of the cleaned copper mesh into the solution was added for $20 \mathrm{~s}$ at room temperature, then using the deionized water to washed the membrane for $3 \mathrm{~min}$ to clear out the residue and it was then dried in the blast drying oven at $60^{\circ} \mathrm{C}$. 


\subsection{Instrumentation and Characterization}

The images of the SEM (the Scanning Electron Microscope) could be gained via a field-emission scanning electron microscope MAIA3 LMH and the images of XRD (the X-ray Diffraction) could be attained via an X-ray diffraction-6100. The images of XPS were gained by using a Thermo Fisher

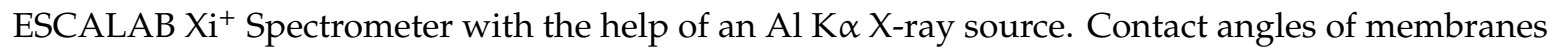
toward oil or water were measured by using the DSA100 machine at room temperature. The volume of the tested liquid (water or oil droplets) was $4 \mu \mathrm{L}$. To measure the water and oil contact angles, the droplets were positioned directly over the surface of the membrane and in the air, respectively. During the underwater oil contact angle measurement, 1,2-dichloroethane was chosen as tested oil due to its high density as compared to water and the membranes were secured in a water-filled transparent quartz vessel during the measurement. We used the average value of three measurements carried out at different locations on the one membrane sample to characterize the contact angle of the membrane. The oil content in the water after the separation was measured by the Total Organic Carbon Analyzer (vario TOC, Xi'an West Economics Import \& Export Corporation, Xi'an, China).

\section{Characterizations and the Separation Results of the Membranes}

\subsection{Microstructure on the Surface of the Membranes}

The SEM images of the $\mathrm{Cu}(\mathrm{OH})_{2}$-CS membrane as well as the Ag-CS membrane are shown in Figure 1. It can be inferred from Figure $1 \mathrm{a}, \mathrm{b}$ that the pore diameter of the mesh is about $40 \mu \mathrm{m}$ and the wire of copper mesh as substrate possessed a glossy surface-the oil smoothly flowed through the hole of such diameter. Figure $1 \mathrm{c}$,d show the prepared membranes having rough surface structures. After reacting with $1 \mathrm{M} \mathrm{K}_{2} \mathrm{~S}_{2} \mathrm{O}_{8}$ and $1 \mathrm{M} \mathrm{NaOH}$ mixed solution, the surface of the $\mathrm{Cu}(\mathrm{OH})_{2}-\mathrm{CS}$ membrane has an interval nanoneedle structure (Figure 1c,e)" Figure 1d,f show the feathery composite structure with the micronanoscales over the external surface of the Ag-CS membrane, which was made by immersing the original copper mesh in the $0.1 \mathrm{M} \mathrm{AgNO}_{3}$ solution for about $20 \mathrm{~s}$. We have tried several times to fabricate the Ag-CS membrane with an Ag structure generated on the surface of the membrane, but the results were similar with that showed in Figure 1d. The reason for the nonuniform-generated coating is the length of the reaction time.

In comparison, we can obviously see the difference between the nanoneedle structure generated on the surface of $\mathrm{Cu}(\mathrm{OH})_{2}$-CS membrane and the feathery structure with micronanoscales on the Ag-CS membrane. The wettability of the solid surface is determined by both physical and chemical factors, such as the roughness of the surface and the hydrophobicity of some of the groups existing on the solid surface, respectively. The hierarchical feathery micro/nanostructure provides considerable roughness on the membrane surface compared with the nanoneedle structure, which may be more advantageous for the selective wettability of the membranes because it enhances the hydrophilicity in air and underwater-oleophobicity in water as per the Wenzel model [47]. For the mechanical strength of the generated coatings on the surface of membranes, Figure 1g,h demonstrate that the coatings' thickness on the membranes' surfaces was nearly $10 \mathrm{um}$ and ensured the reusability of the membranes. 

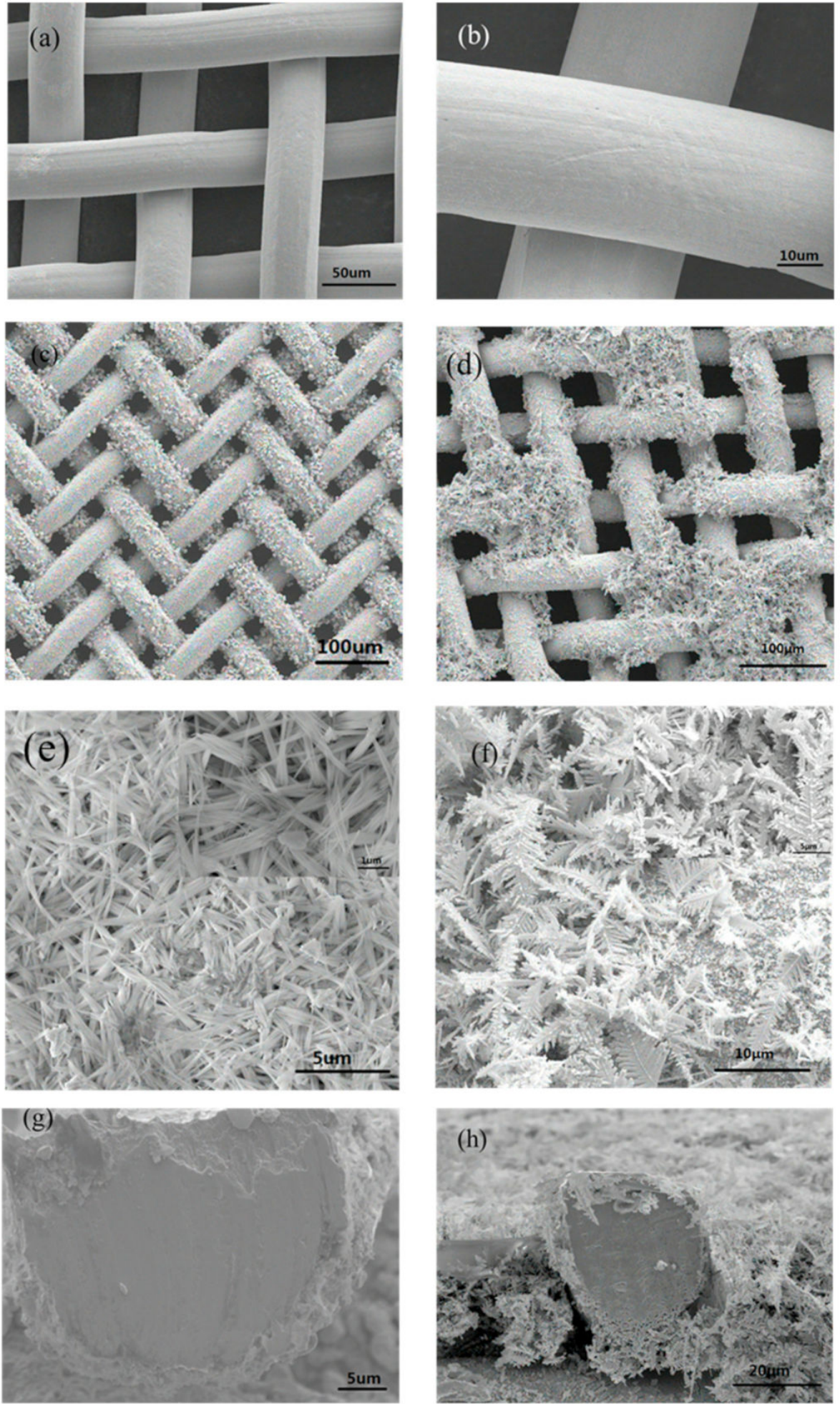

Figure 1. SEM images of the copper mesh substrate and the two prepared membranes: (a) SEM (the Scanning Electron Microscope) image of the original copper mesh; (b) a high-magnification image the copper mesh as substrate before chemical reaction; (c) the SEM image with low magnification of $\mathrm{Cu}(\mathrm{OH})_{2}-\mathrm{CS}$ membrane; (d) the SEM image with low magnification of Ag-CS membrane; (e) the $\mathrm{Cu}(\mathrm{OH})_{2}-\mathrm{CS}$ membrane displaying the generated nanoneedle structure; the insert is also the interval nanoneedle structure with high magnification; (f) the Ag-CS membrane displaying the generated micro/nano feathery structure; the insert is also the micro/nano feathery structure with high magnification; (g) the SEM image of the coating generated on a wire of the $\mathrm{Cu}(\mathrm{OH})_{2}-\mathrm{CS}$ membrane; (h) the SEM image of the coating generated on a wire of the Ag-CS membrane. 


\subsection{The Composition of the Prepared Membranes}

The crystal structures were validated by XRD of both the prepared membranes as depicted in Figure 2a,b. The letter " $a$ " marked the $\mathrm{Cu}$ diffraction peaks in Figure 2a,b according to the number 04-0836 in the JCPDS card. In Figure 2a the peaks marked with the letter " $b$ " represent $\mathrm{Cu}(\mathrm{OH})_{2}$ according to the number 13-0420 in the JCPDS card and the letter " $c$ " marked the Ag peaks in Figure $2 \mathrm{~b}$ according to the number 89-3722 in the JCPDS card. Figure 2a clearly shows that the chemical composition of the generated structure on $\mathrm{Cu}(\mathrm{OH})_{2}-\mathrm{CS}$ membrane is primarily $\mathrm{Cu}(\mathrm{OH})_{2}$, while it can also be seen in Figure $2 b$ that the letter " $c$ " is marked Ag-generating on the Ag-CS membrane. The creation of the nanoscale $\mathrm{Cu}(\mathrm{OH})_{2}$ structure on the first membrane and the micro/nanoscale feathery Ag structure on the other membrane are due to the following chemical reaction:

$$
\begin{gathered}
\mathrm{Cu}+\mathrm{K}_{2} \mathrm{~S}_{2} \mathrm{O}_{8}+2 \mathrm{NaOH} \rightarrow \mathrm{Cu}(\mathrm{OH})_{2}+\mathrm{Na}_{2} \mathrm{SO}_{4}+\mathrm{K}_{2} \mathrm{SO}_{4} \\
\mathrm{Cu}+\mathrm{AgNO}_{3} \rightarrow \mathrm{Cu}\left(\mathrm{NO}_{3}\right)_{2}+\mathrm{Ag}
\end{gathered}
$$
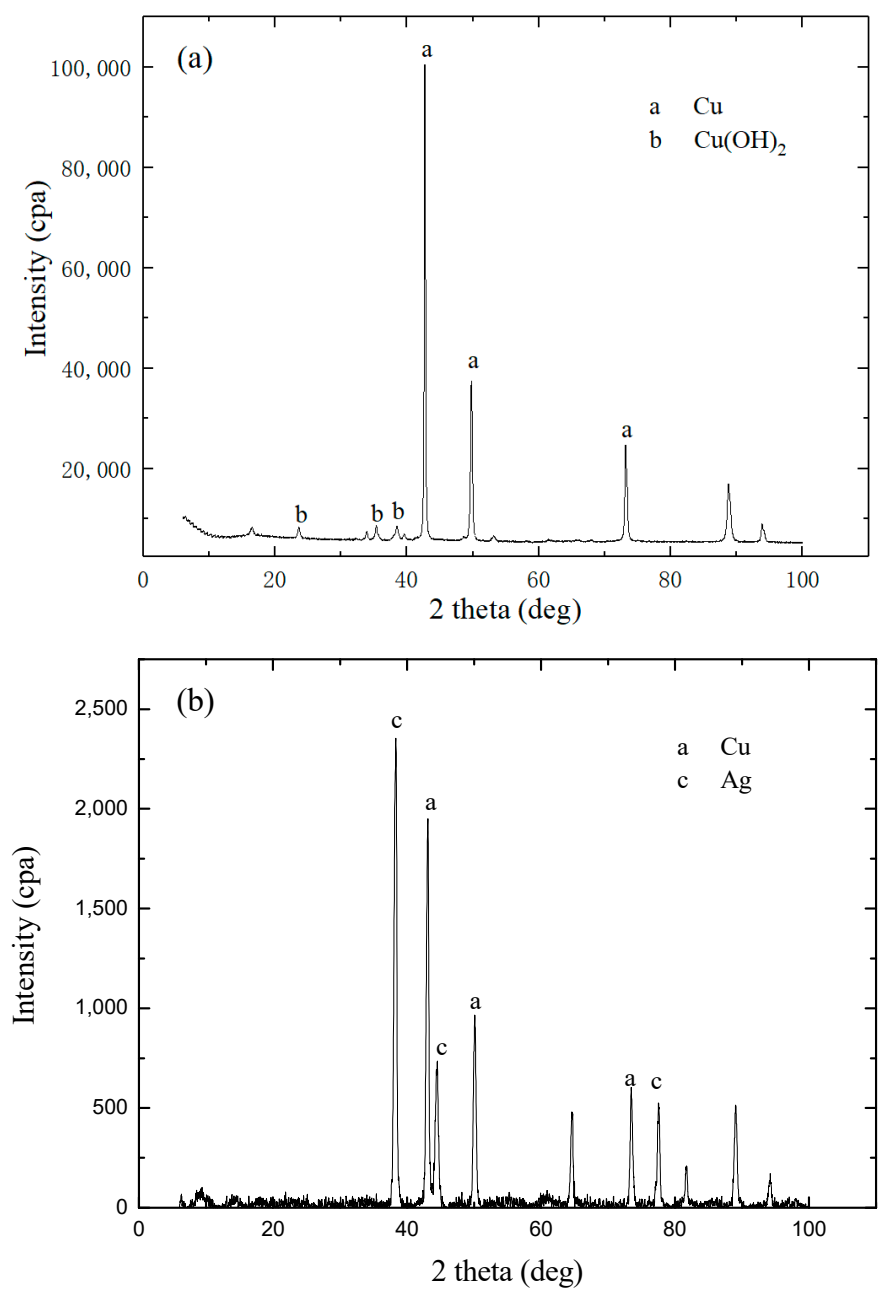

Figure 2. XRD (the X-ray Diffraction) images of the prepared membranes: (a) XRD image of the $\mathrm{Cu}(\mathrm{OH})_{2}-\mathrm{CS}$ membrane; (b) XRD image of the Ag-CS membrane.

In Reaction (1), an oxidation reaction occurred, and the $\mathrm{K}_{2} \mathrm{~S}_{2} \mathrm{O}_{8}$ oxidizes the $\mathrm{Cu}$ substrate to $\mathrm{Cu}(\mathrm{OH})_{2}$ raised at the external surface of the copper mesh. That is the chemical development process for fabrication of the $\mathrm{Cu}(\mathrm{OH})_{2}-\mathrm{CS}$ membrane. In Reaction (2), the $\mathrm{C} 9 \mathrm{u}$ substrate was oxidized to $\mathrm{Cu}^{2+}$ while $\mathrm{Ag}^{+}$in the $0.1 \mathrm{M} \mathrm{AgNO}_{3}$ solution was reduced to $\mathrm{Ag}$ and then raised over the substrate surface. 
The product $\mathrm{Cu}(\mathrm{OH})_{2}$ and $\mathrm{Ag}$ appeared on the two membranes due to the above mentioned two chemical reactions is consistent with the outcomes of the XRD testing.

To further verify the structure's chemical composition generated over the membranes' surfaces, the results of XPS test in Figure 3a,b are also shown. From Figure 3a, it can be found that $\mathrm{Cu}^{2+}$ lies on the $\mathrm{Cu}(\mathrm{OH})_{2}-\mathrm{CS}$ membrane, indicating that a portion of $\mathrm{Cu}$ substrate was oxidized. XRD test results as shown in Figure 2a, along with these findings, indicate that the generated structure on the surface of $\mathrm{Cu}(\mathrm{OH})_{2}-\mathrm{CS}$ membrane is $\mathrm{Cu}(\mathrm{OH})_{2}$. Figure $3 \mathrm{~b}$ clearly displays that Ag exists on the surface of the Ag-CS membrane and this conclusion is in line with the outcome of XRD test. In this case, considering with the test outcomes of XRD shown in Figure 2b, it can be determined that the generated feathery micro/nanocomposite structure on the Ag-CS membrane surface is Ag.
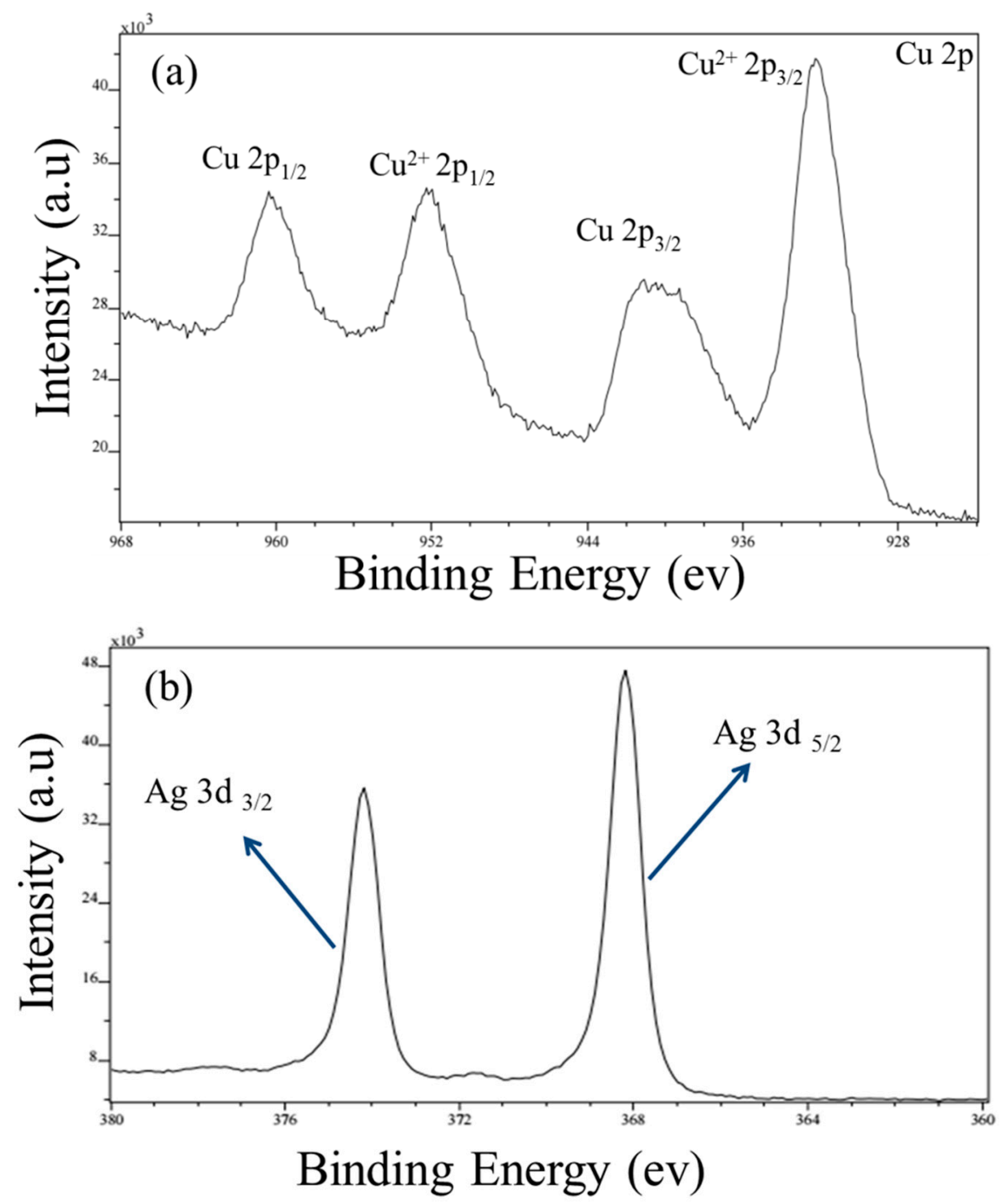

Figure 3. XPS (X-ray Photoelectron Spectrometer) images of the fabricated membranes: (a) XPS image of the $\mathrm{Cu}(\mathrm{OH})_{2}-\mathrm{CS}$ membrane; (b) XPS image of the Ag-CS membrane.

\subsection{Wettability of the Prepared Membranes}

The oil and water contact angle were used to characterize the wettability of the membrane surface. When measuring the water and oil contact angles in the air, water droplet and oil droplet were released directly onto the membranes, when using the underwater oil contact angle to characterize the underwater-superoleophobicity of membranes, which is fixed in transparent quartz filled with water. Figure $4(\mathrm{a} 1, \mathrm{a} 2)$ show the diesel droplet and water droplet contact with the unreacted copper mesh substrate in air; the oil contact angle (OCA) and the water contact angle (WCA) were nearly $0^{\circ}$ and $78.1^{\circ}$, 
respectively, and the unreacted copper mesh showed superoleopholicity and hydrophilicity. Figure $4 b, c$ clearly displayed the $\mathrm{Cu}(\mathrm{OH})_{2}-\mathrm{CS}$ membrane and Ag-CS membrane were superlyophilic in air as they come in contact with water and diesel, also, the contact angles were close to $0^{\circ}$. From Figure 4(a2), Figure 1e,f, we can imply that these two membranes both have a rather high roughness. The Wenzel model [47] also suggests that the rather high roughness of surfaces turn the hydrophilicity in air to superhydrophilicity of the membranes. For the same reason, water comes in contact with the membranes and the oil contact angle was nearly $0^{\circ}$. Moreover, when touching other oil types like gasoline and hexane etc., these two types of prepared membranes also displayed superoleophilicity performance in the air, which means such oil types can smoothly spread onto the membranes.

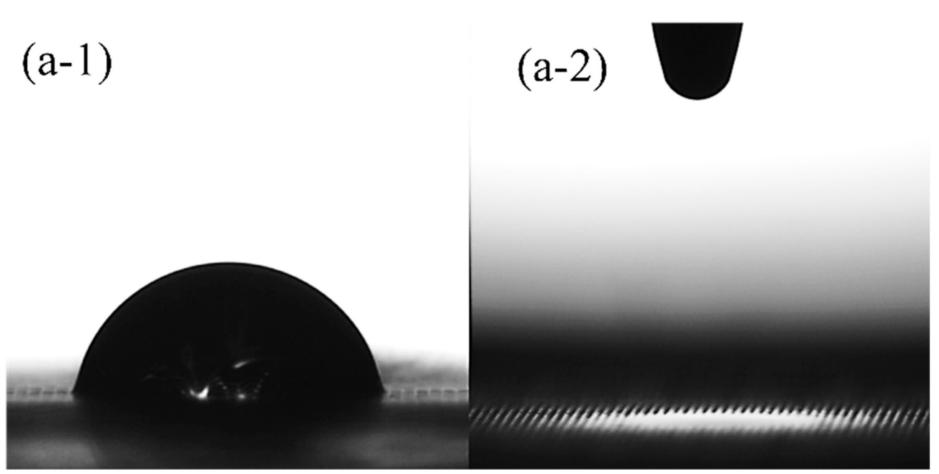

(a)

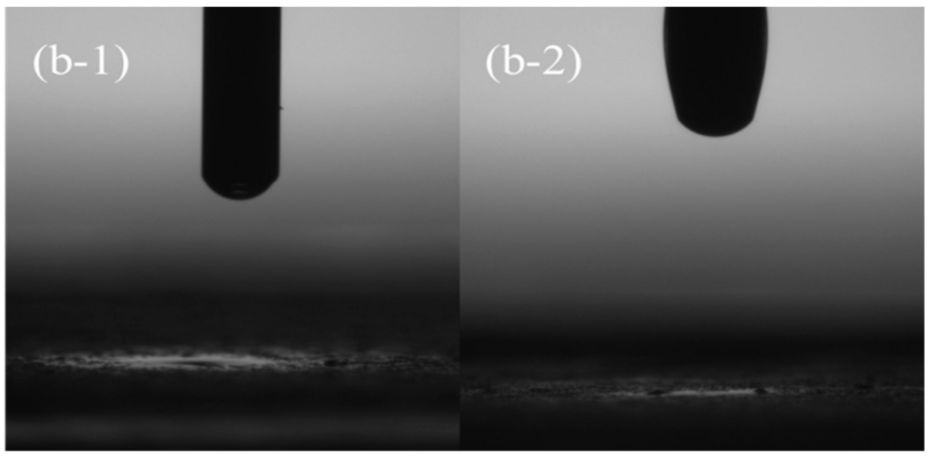

(b)

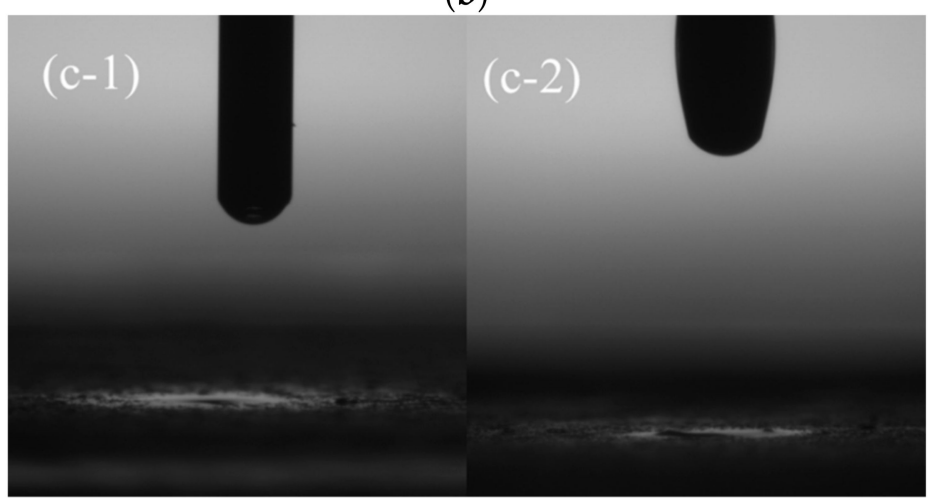

(c)

Figure 4. The contact angles of water and oil droplets when touching the original mesh and prepared membranes in the air. (a-1) The contact angle of water droplet on the surface of the unreacted copper mesh substrate in the air; (a-2) the contact angle of oil droplet on the surface of the unreacted copper mesh in the air; (b-1) the contact angle of a water droplet on the surface of the $\mathrm{Cu}(\mathrm{OH})_{2}-\mathrm{CS}$ membrane in the air; (b-2) the contact angle of an oil droplet on the surface of the $\mathrm{Cu}(\mathrm{OH})_{2}-\mathrm{CS}$ membrane in the air; (c-1) the contact angle of a water droplet on the surface of the Ag-CS membrane in the air; (c-2) the contact angle of an oil droplet on the surface of the Ag-CS membrane in the air. 
Since the sym-dichloroethane is heavier than water, sym-dichloroethane was chosen as the tested oil to measure the underwater oil contact angle (UWOCA). Figure 5a,b show the superoleophobic performance of tested oil over the $\mathrm{Cu}(\mathrm{OH})_{2}-\mathrm{CS}$ and Ag-CS membranes underwater and the underwater oil contact angles of these two prepared membranes i.e., $160.3^{\circ}$ and $156.7^{\circ}$, respectively. The large contact angle values indicate that both membranes exhibited strong rejection toward oil droplets underwater and the membranes exhibited underwater-superoleophobicity. This may have occurred due to the fact that the superhydrophilic membranes surfaces were employed by water and its molecules were trapped inside of the generated, rather rough, structures on the surface and made the whole three-phase system achieve a state with relatively lower energy. The gas-liquid-solid (gas-oil-surface) interface on the membrane surface was changed into a liquid-liquid-solid (water-oil-surface) interface. As the membranes touched the oils, the oil molecules were unable to travel into the pore channels of membranes because the membranes blocked the oil molecules from swapping with water molecules and disrupt the relatively stable state with lower energy; in this case, the membranes naturally behaved with superhydrophilicity and underwater-superoleophobicity.
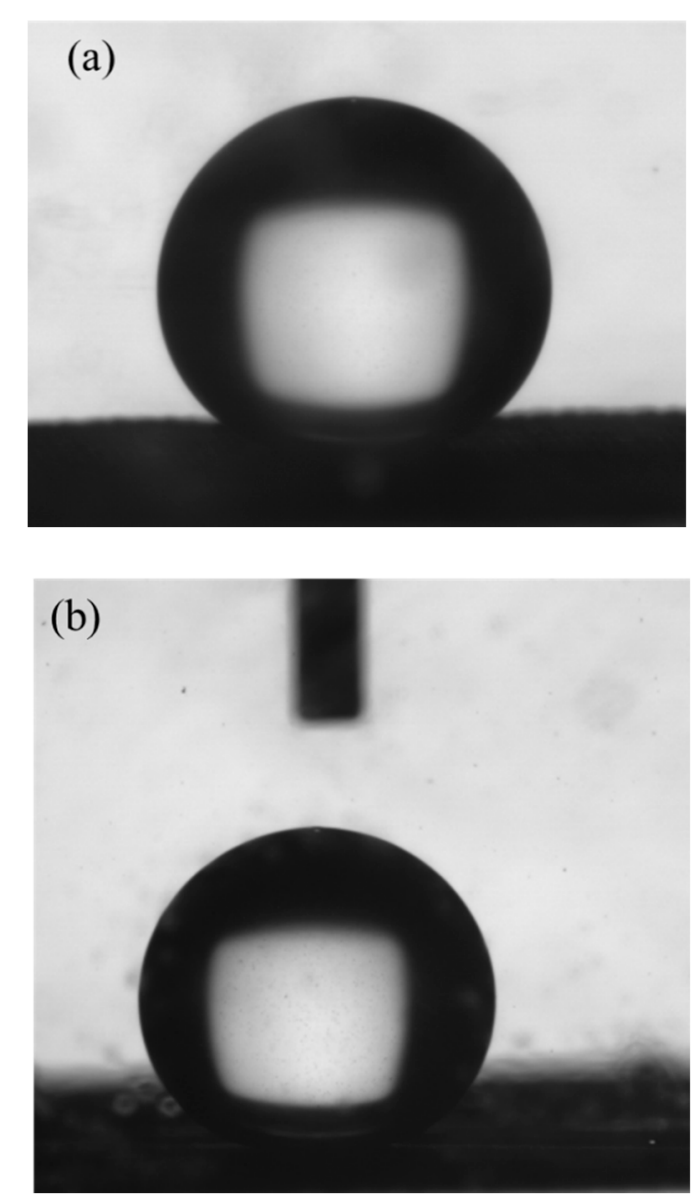

Figure 5. Underwater oil contact angles of the prepared membranes: (a) the superoleophobic performance of a sym-dichloroethane droplet when in contact with the $\mathrm{Cu}(\mathrm{OH})_{2}-\mathrm{CS}$ membrane underwater; (b) the superoleophobic performance of a sym-dichloroethane droplet when in contact with the Ag-CS membrane underwater.

\subsection{Single Component Oil/Water Mixture Separation}

Diesel was chosen as the tested oil to carry out the single component oil/water mixture separation experiment. Figure 6 displays the photograph of the separation process, including before separation, in separation and after separation. From Figure 6, it can be seen that the prepared membranes were clamped in-between the two glass tubes, with each tube have two hooks and the tubes were fastened 
using four rubber bands to ensure the membranes were held firmly. Because the membranes displayed superhydrophilicity simultaneously with underwater-superoleophobicity and the tested oil diesel was lighter than water in the separation, the separation device was placed vertically. After being wetted beforehand, the water smoothly passed through the membrane while the diesel was repelled and stayed above the membrane. When the mixture consisting of water and diesel (dyed with Oil Red O) was poured, the water flowed across the membrane swiftly due to gravity, while diesel was stopped and remained above the membrane (please refer to the video in the Supplementary Information).

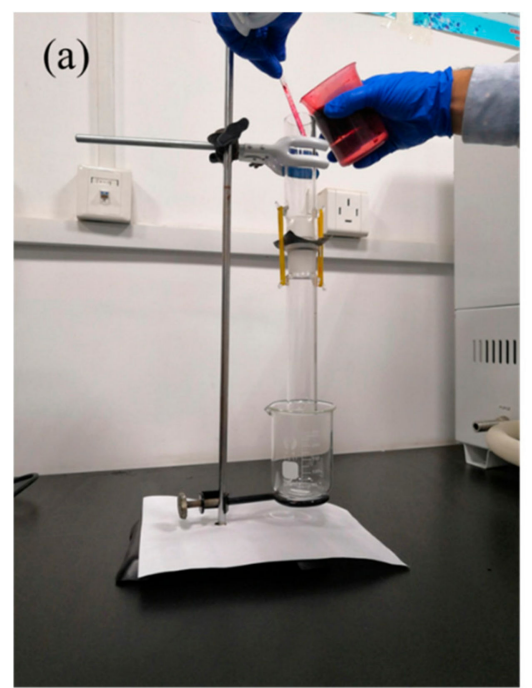

Before separation

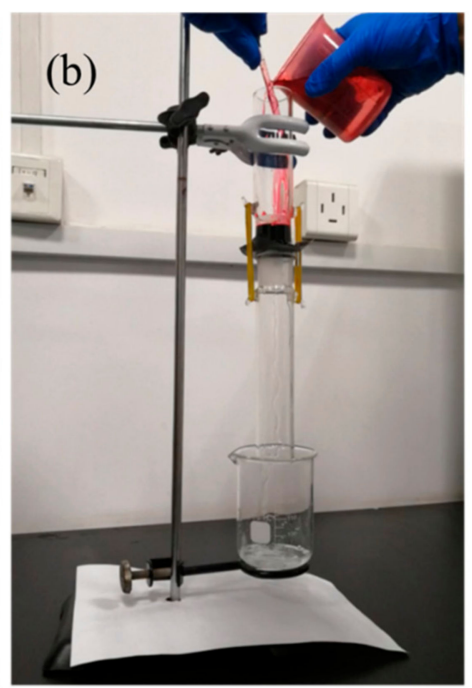

During separation

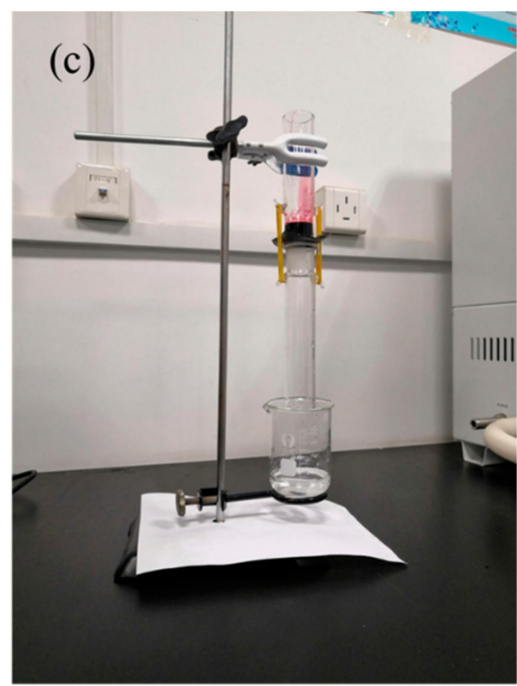

After separation

Figure 6. The image of separation process: (a) the image of the process before separation; (b) the image of the process during separation; (c) the image of the process after separation.

The separation of oil/water mixtures consisting of hexadecane/water or hexane/water or gasoline/ water etc. were also carried out successfully. There was no visible oil (dyed with Oil Red O) in the water after the separation was carried out, while the constituents of the oil were tested by the TOC (the Total Organic Carbon). The efficiency of the separation was evaluated using following equation:

$$
\mathrm{R}(\%)=\left(1-\frac{m_{0}}{m_{c}}\right) * 100 \%
$$

In the equation, $m_{0}$ represents the result of the TOC value, and $m_{\mathrm{c}}$ denotes the oil content of the oil/water mixture before separation. Figure $7 \mathrm{a}, \mathrm{b}$ clearly display the results of TOC values and the calculated separation efficiency of the prepared membranes, respectively. Figure $7 \mathrm{a}, \mathrm{b}$ show that the separation efficiency of the prepared membranes decreased with increasing reuse time, nevertheless, two membranes still performed well and kept high separation efficiency beyond $99.7 \%$ after 10 instances of separation. In the experiment, the used membranes were soaked in ethanol for about 5 min. Compared with the $\mathrm{Cu}(\mathrm{OH})_{2}$ - $\mathrm{CS}$ membrane, the Ag-CS membrane showed higher efficiency as well as better reusability in separating the oil/water mixture. 


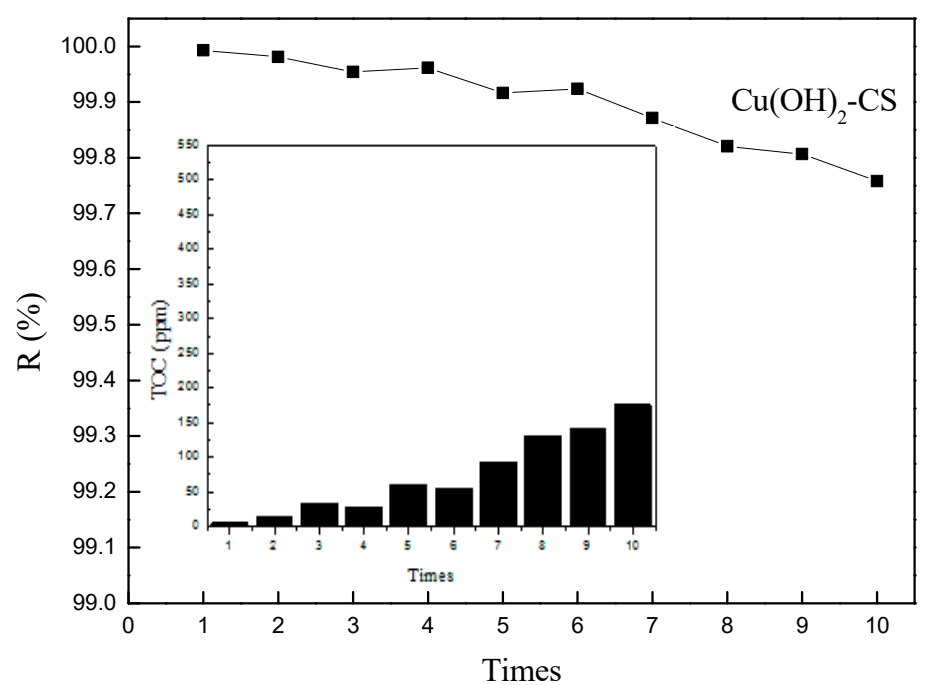

(a)

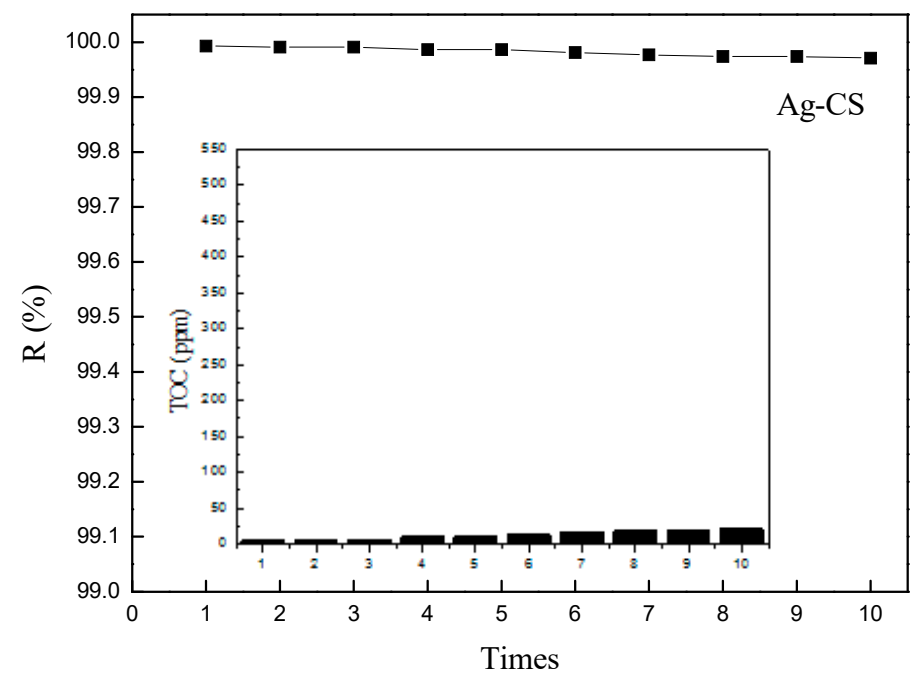

(b)

Figure 7. The separation results of membranes when separating single component oil/water mixture. (a) TOC (the Total Organic Carbon) value and calculated separation efficiency of the $\mathrm{Cu}(\mathrm{OH})_{2}-\mathrm{CS}$ membrane. (b) TOC (the Total Organic Carbon) value and calculated separation efficiency of the Ag-CS membrane.

For further analysis of the reason for the high efficiency of membranes after 10 instances of separation, Figure $8 \mathrm{a}$, b clearly illustrate the $\mathrm{Cu}(\mathrm{OH})_{2}-\mathrm{CS}$ and Ag-CS membrane. From Figure $8 \mathrm{a}, \mathrm{b}$, it can be clearly seen that no visible generated structures were destroyed. For the same reason, no loss of the rough and feathery micro/nanoscale structure on the membranes contributed to the very high efficiency of the membranes after 10 instances of repeated separation. The good performance shown in the experiment will greatly benefit the application of these membranes in practical usage. 

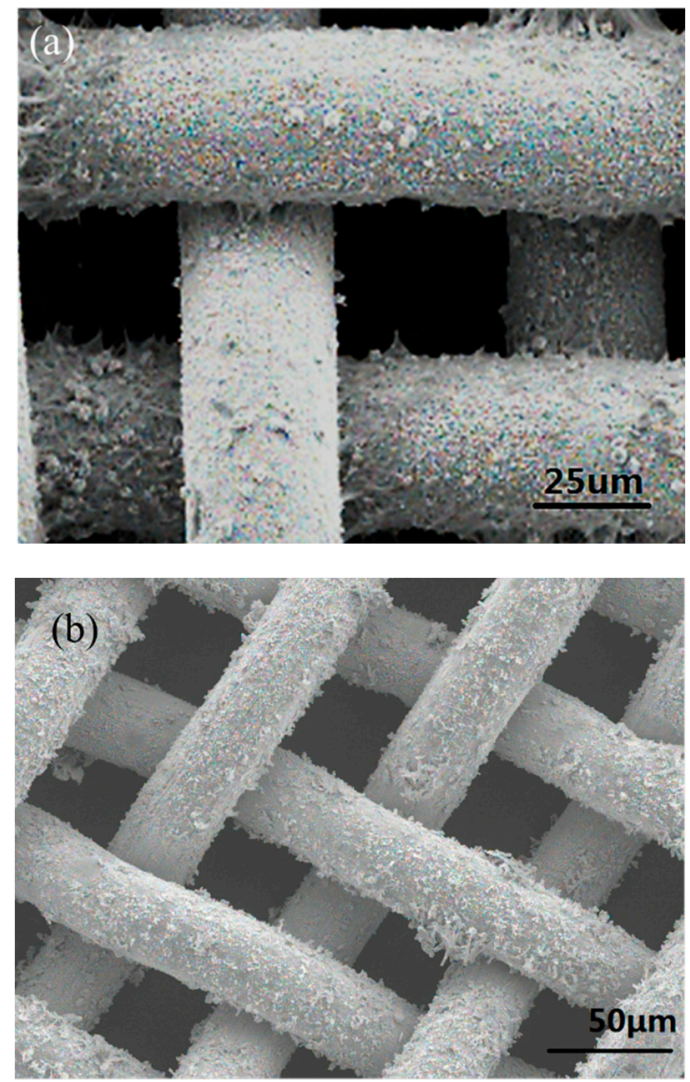

Figure 8. The SEM images of the prepared membranes after repetitive experiment: (a) the SEM image of the $\mathrm{Cu}(\mathrm{OH})_{2}-\mathrm{CS}$ membrane after repetitive experiment; (b) the SEM image of the Ag-CS membrane after repetitive experiment.

For the practical application of the prepared separation membranes, the resistance to acid and alkali solutions, intrusion pressure and liquid flux are also of significant importance. Considering the component and $\mathrm{pH}$ value of actual oil/water mixtures are complex, which may affect the performance of the membranes in the separation experiment, the acid and alkali resistance of the two membranes were tested to ensure the better application of the prepared membranes in practice. The solutions used for the test are hydrochloric acid $(\mathrm{HCl})$ solution with $\mathrm{pH} 1$ and sodium hydroxide $(\mathrm{NaOH})$ solution with $\mathrm{pH}$ 13. These two types of membranes were immersed in the excess acid solution and sodium hydroxide solution for $24 \mathrm{~h}$ and then subjected to separation experiments to test their performance. The $\mathrm{Cu}(\mathrm{OH})_{2}-\mathrm{CS}$ membrane turned bright gold after being immersed in acid solution for $24 \mathrm{~h}$, which indicates that the nanoneedle $\mathrm{Cu}(\mathrm{OH})_{2}$ structure reacted with the acid solution. The $\mathrm{Cu}(\mathrm{OH})_{2}-\mathrm{CS}$ membrane has no obvious change after immersing in sodium hydroxide solution for $24 \mathrm{~h}$ because the preparation process of the nanoneedle $\mathrm{Cu}(\mathrm{OH})_{2}-\mathrm{CS}$ membrane is in alkali solutions, which indicates that the membrane has a good alkali resistance.

The contact angle test showed that the $\mathrm{Cu}(\mathrm{OH})_{2}-\mathrm{CS}$ membrane retained superhydrophilic/ superlipophilic properties in air and underwater-superoleophobicity after immersion. The results of separation experiments exhibited that $\mathrm{Cu}(\mathrm{OH})_{2}-\mathrm{CS}$ membrane also can separate the oil/water mixture with high separation efficiency, although the pressure capacity decreases slightly. This is mainly because the nanoneedle $\mathrm{Cu}(\mathrm{OH})_{2}$ structure reacted with excess acid in solution to form $\mathrm{CuCl}_{2}$ dissolved in the solution. However, the substrate was no longer smooth at this time, because the substrate exhibited a similar etching state with micro-nanostructure after the reaction occurred between nanoneedle $\mathrm{Cu}(\mathrm{OH})_{2}$ structure and acid solution. Moreover, the substrate did not continue to react with the acid solution, so the membrane retained its original wettability characteristics and can be used for oil/water separation. 
For the generated feathery structure on the Ag-CS membrane, there was no obvious change in the appearance after immersing in an acidic solution and in the alkaline solution. The results of the wettability and separation test showed no significant difference between the membrane before and after immersion. As per the analysis, neither $\mathrm{Ag}$ nor the $\mathrm{Cu}$ substrate will react in the nonoxidizing strong acid and strong alkali solution, and there was no significant change in wettability and separation performance.

The intrusion pressure determines how much oil the prepared membranes can support, and in the study, we calculated the intrusion pressure by the following equation:

$$
\begin{gathered}
\Delta P=\frac{2 \gamma}{R}=-\frac{l \gamma \cos \theta_{a}}{A}=-\frac{2 \gamma \cos \theta_{a}}{\pi r} \\
\exp =\rho g h_{\max }
\end{gathered}
$$

In Equation (4), $\Delta P$ represents the intrusion pressures, $\gamma$ represents the surface tension, $\theta_{a}$ is the advancing contact angle, $A$ is the area of the hole of membrane, $l$ is the perimeter of the hole, $R$ is the radius of curvature of the meniscus, $r$ is the radius of the hole. When $\Delta P>0$, additional pressure is required for oil/water mixture to pass the membrane, and when $\Delta P<0$, the mixture can pass through the membrane without additional pressure. It can be seen from Equation (4) that the advancing contact angle and the surface tension cannot be changed-only the parameters of the membrane can be changed when the oil type and the component of surface are determined. When the $\cos \theta_{\mathrm{a}}$ of the superoleophobic membrane is negative and the radius of the holes increase, the $\Delta P$ will decrease. When the $\Delta P$ is too small, a small pressure of oil will make the oil pass through the membrane smoothly and almost no liquid column can be withstood. The column height the membranes can withstand gradually increases with the decrease of the radius of the hole, and when the passing velocity of liquid is greater than the cumulative velocity of the liquid column, separation can be achieved. Therefore, the difference of component and radius between the $\mathrm{Cu}(\mathrm{OH})_{2}-\mathrm{CS}$ and Ag-CS membranes lead to different intrusion pressures of the membranes.

In Equation (5), $\rho$ represents the density of tested oil type (diesel), $g$ denotes the gravitational acceleration, $h_{\max }$ denotes the maximum height of the diesel that prepared membranes were able to support. In the experiment, water passed through membranes smoothly, which means that the intrusion pressure of membranes toward water was 0 because of its superhydrophilicity. However, the membranes also displayed underwater-superoleophobicity, and this made the oil stay above the membranes. With the increase of the oil height at a particular moment, oil permeated and then passed through the membranes, and the maximum bearable height of the prepared membranes was obtained. The maximum height is determined by considering the average of three measurements for each membrane. The maximum height obtained of the $\mathrm{Cu}(\mathrm{OH})_{2}-\mathrm{CS}$ and Ag-CS membrane was $17.0 \mathrm{~cm}$ and $19.2 \mathrm{~cm}$, respectively, as found using Equation (4); the average intrusion pressure of the $\mathrm{Cu}(\mathrm{OH})_{2}-\mathrm{CS}$ and $\mathrm{Ag}-\mathrm{CS}$ membrane were $1445 \mathrm{~Pa}$ and $1632 \mathrm{~Pa}$, respectively (Figure 9). The relatively high intrusion pressures demonstrate that the membrane had the ability to support a large amount of oil/water mixture, which means the prepared membranes have capacity to separate large amounts of oil/water mixture.

As mentioned above, the smaller radius of the hole will lead to lower separation rate, which will limit the application of the membrane in practice. To evaluate the liquid flux, the single component oily wastewater was made by adding $15 \mathrm{~mL}$ diesel and $135 \mathrm{~mL}$ deionized water together, and the liquid flux was calculated by measuring the time that the prepared membranes took to completely separate the oil/water mixture at ambient temperature. Figure 9 clearly shows the liquid flux of the prepared membranes were $3651 \mathrm{Kg} /\left(\mathrm{m}^{2} \cdot \mathrm{h}\right)$ and $3084 \mathrm{Kg} /\left(\mathrm{m}^{2} \cdot \mathrm{h}\right)$. In this study, the liquid flux actually refers to the water flux, and in this case, the liquid flux of prepared membranes was greatly influenced by the flow area and wettability of the membranes. We clearly found that there were highly non-uniform structures on the surface of the Ag-CS membrane, as shown in Figure 1c,d. It illustrates that the flow area of the Ag-CS membrane is small because some holes were blocked by the generated rough 
structures, so the liquid flux of the Ag-CS membrane was much smaller than that of the $\mathrm{Cu}(\mathrm{OH})_{2}-\mathrm{CS}$ membrane. Figure $5 \mathrm{a}, \mathrm{b}$ show the underwater oil contact angles of the prepared membranes were $160.3^{\circ}$ and $156.7^{\circ}$ and the $\mathrm{Cu}(\mathrm{OH})_{2}$-CS membrane is relatively more repellent to oil. The results show that the $\mathrm{Cu}(\mathrm{OH})_{2}-\mathrm{CS}$ membrane attracted more water droplets as compared with the Ag-CS membrane, and water passed through the membrane more smoothly. Considering the two aspects above, the liquid flux of $\mathrm{Cu}(\mathrm{OH})_{2}-\mathrm{CS}$ membrane is larger than that of the Ag-CS membrane, and this is consistent with the result of the practical experiment presented in Figure 9.

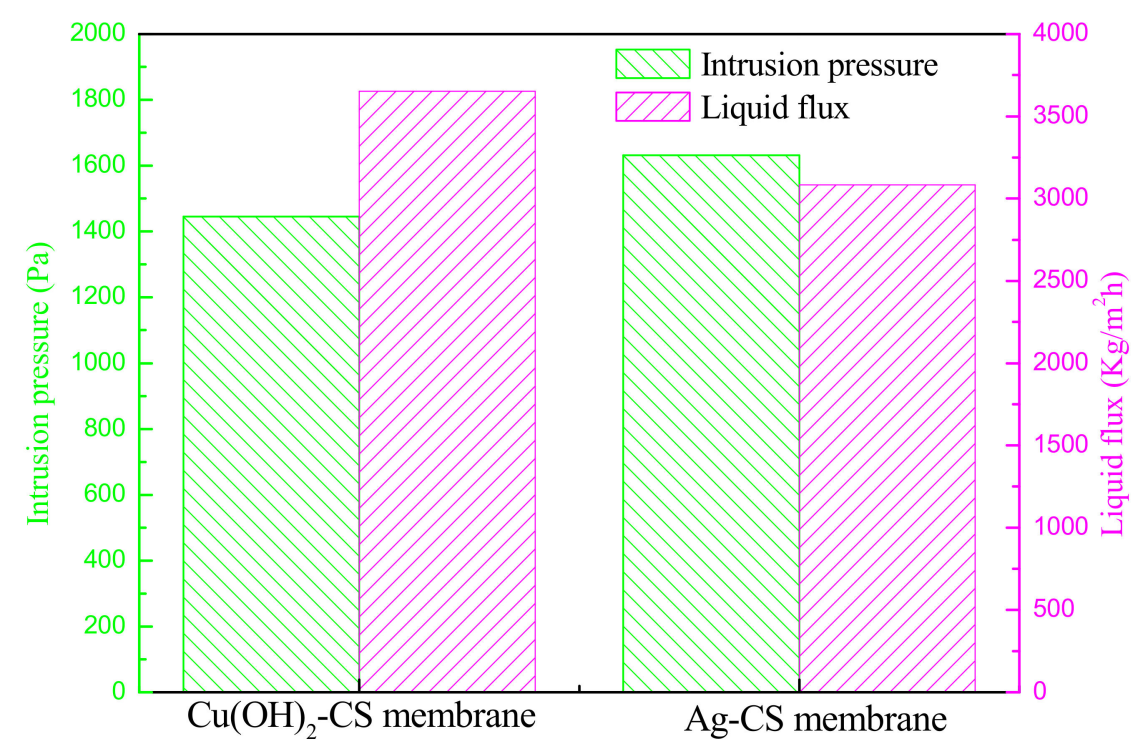

Figure 9. The intrusion pressure and liquid flux of the prepared membranes.

Considering some practical applied conditions mentioned above, including separation efficiency, the resistance to acid and alkali solutions, intrusion pressure and liquid flux, we could find that the Ag-CS membrane showed better performance in the separation of the oil/water mixture compared with the $\mathrm{Cu}(\mathrm{OH})_{2}-\mathrm{CS}$ membrane and the Ag-CS membrane. These results may have a broad range of application. However, there is a limitation that may restrict the wide range of application of the Ag-CS membrane, which is the relatively higher cost compared with that of the $\mathrm{Cu}(\mathrm{OH})_{2}-\mathrm{CS}$ membrane. In the further work, we will continue to study how to fabricate lower-cost membranes with similar properties and practical effects, such as obtaining a micro-structured surface via etching methods and then modifying the surface with some lower-priced materials.

\subsection{Multicomponent Oil/Water Mixtures Separation}

The research was further carried out to the multicomponent oil/water mixture separation in consideration of the practical oily wastewater from factories or living are often contains numerous oil types. Herein, two different types of oils were chosen i.e., sunflower oil and gasoline, to represent macromolecular oils and small molecular oils. So, three different oil/water mixtures were obtained: sunflower oil/water $(15 \mathrm{~mL}+135 \mathrm{~mL})$, gasoline/water $(15 \mathrm{~mL}+135 \mathrm{~mL})$ and sunflower oil/gasoline/water $(7.5 \mathrm{Ml}+7.5 \mathrm{~mL}+135 \mathrm{~m} \mathrm{~L})$. After the oil/water mixtures were prepared, the separation experiments were carried out using the device shown in Figure 6.

Using Equation (3), the separation efficiency of the prepared membranes for multicomponent was evaluated, and the results of TOC value are shown in Figure 10. Figure 10 clearly shows that the prepared membranes all showed notable results for the separation, and the efficiency of the separation was higher than $99.8 \%$. The prepared membranes had even better separation efficiency when the oil/water mixture consisting of macromolecular oil (sunflower oil) was separated as compared with that of small molecular oil (gasoline)/water mixture was separated. Meanwhile, the separation efficiency of 
different oil types (sunflower oil+ gasoline)/water mixture was somewhere in between. The diameter of suspended oil and dispersed oil droplets was 20-150 um and these oils were mostly the same as prepared for the experiment. The Figure $1 \mathrm{c}, \mathrm{d}$ clearly show that there were many uniform structures and highly non-uniform structures existed on the surface of the $\mathrm{Cu}(\mathrm{OH})_{2}$-CS membrane and the Ag-CS membrane respectively. It shows that the pore size of the membranes prepared for the experiment was $40 \mathrm{um}$, i.e., probably larger than that of the gasoline molecular in water, but smaller than that of the sunflower oil. The highly nonuniform structures on the Ag-CS membrane surface further reduced the flow area of the pores. In this case, the prepared membranes likely allowed some small gasoline molecular to pass through but did not allow macro sunflower oil molecules to pass through. Thus, the water sample after separation of sunflower oil/water mixture contained less oil molecules.

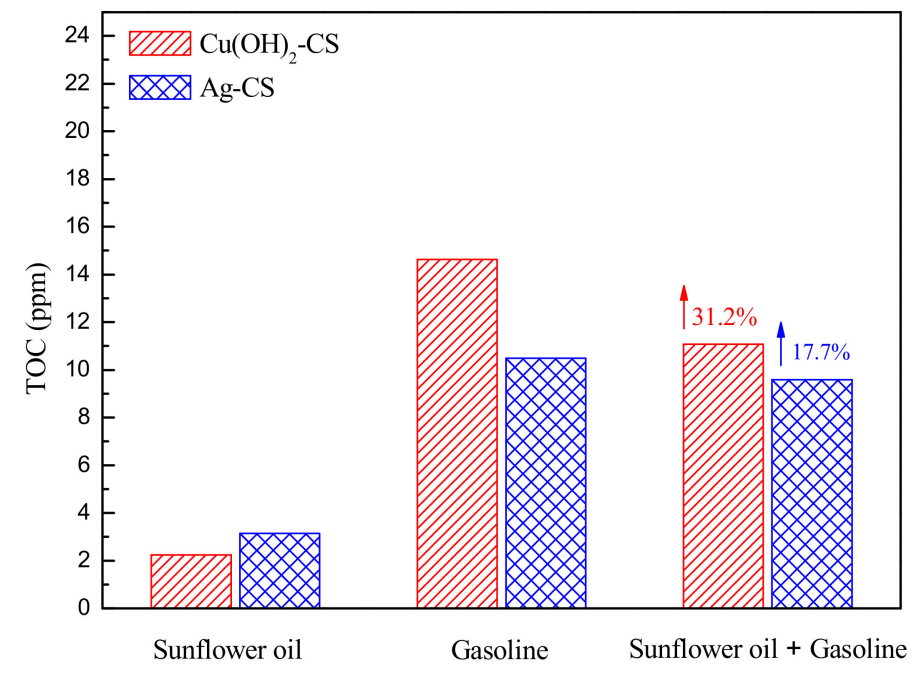

Figure 10. The separation results of prepared membranes for multicomponent oil/water mixture.

By analyzing the TOC data, it was found that the TOC values of prepared membranes are $31.2 \%$ and $17.7 \%$ higher than the mean values $\left(\mathrm{TOC}_{\mathrm{avg}}=\frac{\mathrm{TOC}_{\text {sunflower }}+\mathrm{TOC}_{\text {gasoline }}}{2}\right)$ of the two single oils as displayed in Figure 10. Because of excellent mutual solubility of the sunflower oil and gasoline, a few generated oils were naturally made in the prepared oil/water mixture, with sizes between that of the sunflower oil and gasoline droplets. While separating the multicomponent oil/water mixture, some single component oil droplets passed through the membranes, besides, some formed soluble oil droplets whose size was smaller than that of prepared membranes also passed through the membranes. The feathery micro/nanoscale structure generated on the Ag-CS membrane decreased the flow area as compared with that of the $\mathrm{Cu}(\mathrm{OH})_{2}$-CS membrane. In this case, the increased proportion of the TOC value of $\mathrm{Ag}$-CS membrane was smaller than that of the $\mathrm{Cu}(\mathrm{OH})_{2}-\mathrm{CS}$ membrane.

\section{Conclusions}

In the current study, focused on the copper substrate, two types of membranes with nanoscale needle structure and the micro/nanoscale feathery structure were successfully made by oxidative reaction and in situ chemical replacement reaction. The prepared membranes were used for systematically separating not only oil/water mixture consisting of single component but also multicomponent mixtures. We also tested the permeation pressure and liquid flux of each prepared membranes and studied the effects of microstructure and surface wettability on these two experimental performances. In comparison, while separating the single component oil/water mixture, it was observed that the separation efficiencies of the prepared membranes were above $99.8 \%$, the Ag-CS membrane exhibited higher efficiency as compared to the $\mathrm{Cu}(\mathrm{OH})_{2}$ - $\mathrm{CS}$ membrane after 10 repetitions of the experiment. As a result of the combined effect of generated surface structure and surface wettability, the $\mathrm{Cu}(\mathrm{OH})_{2}$-CS membrane showed a higher permeation pressure and supported larger 
amounts of oil/water mixtures, but in turn, the Ag-CS membrane had higher liquid flux and separated the oil/water mixture more quickly. In the separation for multicomponent oil/water mixture, the prepared membranes all showed good performance with high separation efficiency, and the results of separating multicomponent oil were somehow in between single component oils. The TOC test result of $\mathrm{Cu}(\mathrm{OH})_{2}-\mathrm{CS}$ membrane and Ag-CS membrane were $31.2 \%$ and $17.7 \%$ higher than average of the two oils probably because some new oil droplets created by mutual dissolution passed through the membranes. Nevertheless, the prepared membranes still performed well and maintained high efficiencies in separation, thus proving that the prepared membranes, especially the Ag-CS membrane with a feathery micro/nanocomposite structure, could be an exciting application in the field of oil/water separation.

Supplementary Materials: The video about the separation process as the supplementary material is available online at http://www.mdpi.com/1996-1073/12/23/4564/s1.

Author Contributions: The contributions of each author to the research are as follows: Conceptualization, J.Y., C.C., B.Q., J.W., M.A.Q.; Methodology, J.Y., B.Q., J.W., and M.A.Q.; Software, J.Y. and C.C.; Resources, J.Y., and M.A.Q.; Writing-Original Draft Preparation, J.Y.; Writing-Review \& Editing, B.Q., J.W. and M.A.Q.

Funding: This research was funded by the project of National Natural Science Foundation of China, China (No. 51776168, No.51636006, No. 51611130060), the Natural Science Foundation of Jiangsu Province, China (No. BK20171236), Funds of International Cooperation and Exchange of the National Natural Science Foundation of China (Research collaboration NSFC-VR) (No. 51961135102), Shaanxi Creative Talents Promotion Plan-Technological Innovation Team (2019TD-039), The Fundamental Research Funds for the Central Universities (Creative Team Plan No.cxtd2017004 in Xi'an Jiaotong University), and the Fundamental Research Funds for the Central Universities, China (No. xjj2017086). The APC was funded by National Natural Science Foundation of China (51776168).

Conflicts of Interest: All authors have read and approved the final submitted manuscript. No conflicts of interest are involved in this work.

\section{References}

1. Cheryan, M.; Rajagopalan, N. Membrane processing of oily streams. Wastewater treatment and waste reduction. J. Membr. Sci. 1998, 151, 13-28. [CrossRef]

2. Padaki, M.; Murali, R.S.; Abdullah, M.S.; Misdan, N.; Moslehyani, A.; Kassim, M.A.; Hilal, N.; Ismail, A.F. Membrane technology enhancement in oil-water separation. A review. Desalination 2015, 357, $197-207$. [CrossRef]

3. Chan, Y.J.; Chong, M.F.; Chung, L.L.; Hassell, D.G. A review on anaerobic-aerobic treatment of industrial and municipal wastewater. Chem. Eng. J. 2009, 155, 1-18. [CrossRef]

4. Gao, C.; Sun, Z.; Kan, L.; Chen, Y.N.; Cao, Y.Z.; Zhang, S.Y.; Lin, F. Integrated oil separation and water purification by a double-layer $\mathrm{TiO}_{2}$-based mesh. Energy Environ. Sci. 2013, 6. [CrossRef]

5. Vemu, S.; Pinnamaneni, U.B. Cross-flow microfiltration of industrial oily wastewater: Experimental and theoretical consideration. Sep. Sci. Technol. 2011, 46, 1213-1223.

6. Lin, F.; Zhang, Z.Y.; Mai, Z.H.; Liu, B.Q.; Lei, J.; Zhu, D.B. A super-hydrophobic and super-oleophilic coating mesh film for the separation of oil and water. Angew. Chem. Int. Ed. 2010, 43, 2012-2014.

7. Ivshina, I.B.; Kuyukina, M.S.; Krivoruchko, A.V.; Elkin, A.A.; Makarov, S.O.; Cunningham, C.J.; Peshkur, T.A.; Atlas, R.M.; Philp, J.C. Oil spill problems and sustainable response strategies through new technologies. Environ. Sci. Process. Impacts 2015, 17, 1201-1219. [CrossRef]

8. Zhang, L.; Wu, J.; Wang, Y.; Long, Y.; Zhao, N.; Xu, J. Combination of bioinspiration: A general route to superhydrophobic particles. J. Am. Chem. Soc. 2012, 134. [CrossRef]

9. Nguyen, D.D.; Tai, N.H.; Lee, S.B.; Kuo, W.S. Superhydrophobic and superoleophilic properties of graphenebased sponges fabricated using a facile dip coating method. Energy. Environ. Sci. 2012, 7, 7908-7912. [CrossRef]

10. Jenssen, B.M. Review article: Effects of oil pollution, chemically treated oil, and cleaning on thermal balance of birds. Environ. Pollut. 1994, 86. [CrossRef]

11. Wang, S.; Song, Y.; Jiang, L. Microscale and nanoscale hierarchical structured mesh films with superhydrophobic and superoleophilic properties induced by long-chain fatty acids. Nanotechnology 2007, 18, 15103-15105. [CrossRef] 
12. Adebajo, M.O.; Frost, R.L.; Kloprogge, J.T.; Carmody, O.; Kokot, S. Porous materials for oil spill cleanup: A review of synthesis and absorbing properties. J. Porous Mat. 2003, 10, 59-170. [CrossRef]

13. Srijaroonrat, P.; Julien, E.; Aurelle, Y. Unstable secondary oil/water emulsion treatment using ultrafiltration: Fouling control by backflushing. J. Membr. Sci. 1999, 159, 11-20. [CrossRef]

14. Darling, S.B. Perspective: Interfacial materials at the interface of energy and water. J. Appl. Phys. $2018,124$. [CrossRef]

15. Zhang, L.B.; Zhang, Z.H.; Peng, W. Smart surfaces with switchable superoleophilicity and superoleophobicity in aqueous media: Toward controllable oil/water separation. NPG Asia Mater. 2012, 4. [CrossRef]

16. Crick, C.R.; Gibbins, J.A.; Parkin, I.P. Superhydrophobic polymer-coated copper-mesh; membranes for highly efficient oil-water separation. J. Mater. Chem. A 2013, 1. [CrossRef]

17. Kammerer, M.; Mastain, O.; Dréan-Quenech'Du, S.L.; Pouliquen, H.; Larhantec, M. Liver and kidney concentrations of vanadium in oiled seabirds after the Erika wreck. Sci. Total Environ. 2004, 333, $295-301$. [CrossRef]

18. Kajitvichyanukul, P.; Hung, Y.T.; Wang, L.K. Oil Water Separation. Handbook of Environmental Engineering; Wang, L.K., Hung, Y.-T., Shammas, N.K., Eds.; Springer: Berlin, Germany, 2006.

19. Kwon, W.T.; Park, K.; Han, S.D.; Yoon, S.M.; Kim, J.Y.; Bae, W.; Rhee, Y.W. Investigation of water separation from water-in-oil emulsion using electric field. J. Ind. Eng. Chem. 2010, 16, 684-687. [CrossRef]

20. Eow, J.S.; Ghadiri, M.; Sharif, A.O. Electrostatic and hydrodynamic separation of aqueous drops in a flowing viscous oil. Chem. Eng. Process. Process Intensif. 2002, 41, 649-657. [CrossRef]

21. Hanafy, M.; Nabih, H.I. Treatment of oily wastewater using dissolved air flotation technique. Energy Sources 2007, 29, 143-159. [CrossRef]

22. Yong, J.; Chen, F.; Yang, Q.; Bian, H.; Du, G.Q.; Shan, C.; Huo, J.L.; Fang, Y.; Hou, H. Oil-Water Separation: Oil-Water Separation: A Gift from the Desert. Adv. Mater. Interfaces 2016, 3. [CrossRef]

23. Yang, J.; Zhang, Z.Z.; Xu, X.H.; Zhu, X.T.; Men, X.H.; Zhou, X.Y. Superhydrophilic-superoleophobic coatings. J. Mater. Chem. 2012, 22, 2834-2837. [CrossRef]

24. Zhang, F.; Zhang, W.B.; Shi, Z.; Wang, D.; Jin, J. Nanowire-Haired inorganic membranes with superhydrophilicity and underwater ultralow adhesive superoleophobicity for high-efficiency oil/water separation. Adv. Mater. 2013, 25, 4192-4198. [CrossRef]

25. Xue, Z.X.; Liu, M.J.; Jiang, L. Recent developments in polymeric superoleophobic surfaces. J. Polym. Sci. Part B Polym. Phys. 2012, 50, 1209-1224. [CrossRef]

26. Sun, T.L.; Lin, F.; Gao, X.F.; Jiang, L. Bioinspired surfaces with special wettability. Acc. Chem. Res. 2005, 38, 644-652. [CrossRef]

27. Lin, F.; Zhang, Y.N.; Xi, J.M.; Zhu, Y.; Wang, N.; Xia, F.; Jiang, L. Petal effect: A superhydrophobic state with high adhesive force. Langmuir 2008, 24, 4114-4119.

28. Feng, X.J.; Jiang, L. Design and creation of superwetting/antiwetting surfaces. Adv. Mat. 2010, 18, 3063-3078. [CrossRef]

29. Zhang, Y.L.; Xia, H.; Kim, E.Y.; Sun, H.B. Recent developments in superhydrophobic surfaces with unique structural and functional properties. Soft Matter 2012, 8, 11217. [CrossRef]

30. Blossey, R. Self-cleaning surfaces-Virtual realities. Nat. Mat. 2003, 2, 301-306. [CrossRef]

31. Zhang, J.; Seeger, S. Superoleophobic coatings with ultralow sliding angles based on silicone nanofilaments. Angew. Chem. Inte. Ed. 2011, 50, 6652-6656. [CrossRef]

32. Roach, P.; Shirtcliffe, N.J.; Newton, M.I. Progess in superhydrophobic surface development. Soft Matter 2008, 4, 224-240. [CrossRef]

33. Lafuma, A.; Quéré, D. Superhydrophobic states. Nature Mater. 2003, 2, 457-460. [CrossRef] [PubMed]

34. Zhang, X.; Shi, F.; Niu, J.; Jiang, Z.Q. Superhydrophobic surfaces: From structural control to functional application. J. Mater. Chem. 2008, 18, 621-633. [CrossRef]

35. Cheng, M.J.; Gao, Y.F.; Guo, X.P.; Shi, Z.Y.; Chen, J.F.; Shi, F. A functionally integrated device for effective and facile oil spill cleanup. Langmuir 2011, 27, 7371-7375. [CrossRef] [PubMed]

36. Erbil, H.Y.; Demirel, A.L.; Avci, Y.; Mert, O. Transformation of a simple plastic into a superhydrophobic surface. Science 2003, 299, 1377-1380. [CrossRef] [PubMed]

37. Xue, Z.X.; Sun, Z.X.; Cao, Y.Z.; Chen, Y.N.; Tao, L.; Li, K.; Lin, F.; Fu, Q.; Wen, Y. Superoleophilic and superhydrophobic biodegradable material with porous structures for oil absorption and oil-water separation. RSC Adv. 2013, 3, 23432-23437. [CrossRef] 
38. Zhang, J.L.; Huang, W.H.; Han, Y.C. A composite polymer film with both superhydrophobicity and superoleophilicity. Macromol. Rapid Commun. 2010, 27, 804-808. [CrossRef]

39. Tu, C.W.; Tsai, C.H.; Wang, C.F.; Kuo, S.W.; Chang, F.C. Fabrication of superhydrophobic and superoleophilic polystyrene surfaces by a facile one-step method. Macromol. Rapid Commun. 2010, 28, 2262-2266. [CrossRef]

40. Choi, H.O.; Zhang, K.; Dionysiou, D.D. Effect of permeate flux and tangential flow on membrane fouling for wastewater treatment. Sep. Purif. Technol. 2015, 45, 68-78. [CrossRef]

41. Huang, Y.; Zha, G.Y.; Luo, Q.J.; Zhang, J.X.; Zhang, F.; Li, X.H.; Zhao, S.F.; Zhu, W.P.; Li, X.D. The construction of hierarchical structure on Ti substrate with superior osteogenic activity and intrinsic antibacterial capability. Sci. Rep. 2014, 4, 6172. [CrossRef]

42. Zheng, J.F.; He, A.H.; Li, J.X.; Han, C.C. Studies on the controlled morphology and wettability of polystyrene surfaces by electrospinning or electrospraying. Polymer 2006, 47, 7095-7102. [CrossRef]

43. Wang, B.; Liang, W.X.; Guo, Z.G.; Liu, W.M. Biomimetic super-lyophobic and super-lyophilic materials applied for oil/water separation: A new strategy beyond nature. Chem. Soc. Rev. 2015, 44, 336-361. [CrossRef] [PubMed]

44. Yang, H.C.; Xie, Y.S.; Chan, H.; Narayanan, B.; Chen, L.; Waldman, R.Z.; Sankaranarayanan, S.K.R.S.; Elam, J.W.; Darling, S.B. Crude-oil-repellent membranes by atomic layer deposition: Oxide interface engineering. ACS Nano 2018, 12, 8678-8685. [CrossRef] [PubMed]

45. Kota, A.K.; Kwon, G.B.; Choi, W.J. Hygro-responsive membranes for effective oil-water separation. Nat. Commun. 2012, 3, 1025. [CrossRef]

46. Zhu, X.T.; Zhang, Z.Z.; Men, X.H.; Yang, J.; Wang, K.; Xu, X.H.; Zhou, X.Y.; Xue, Q.J. Robust superhydrophobic surfaces with mechanical durability and easy repairability. J. Mater. Chem. 2011, 21, 15793-15797. [CrossRef]

47. Wenzel, R.N. Resistance of solid surfaces to wetting by water. Ind. Eng. Chem. 1936, 28, 988-994. [CrossRef]

(C) 2019 by the authors. Licensee MDPI, Basel, Switzerland. This article is an open access article distributed under the terms and conditions of the Creative Commons Attribution (CC BY) license (http://creativecommons.org/licenses/by/4.0/). 